Volume 9. No. 3, March 2021

International Journal of Emerging Trends in Engineering Research

Available Online at http://www.warse.org/IJETER/static/pdf/file/ijeter06932021.pdf

https://doi.org/10.30534/ijeter/2021/06932021

\title{
A Meticulous Method for the Measurement of Partial Discharges in Gas Insulated Switchgears
}

\author{
Shaik Mohammad Tayyab ${ }^{1}$, Prof. K. Chandra Sekhar ${ }^{2}$ \\ ${ }^{1}$ Research Scholar - Dept. of E.E.E, Acharya Nagarjuna University, India, tayyab2991@ gmail.com \\ ${ }^{2}$ H.O.D - Dept. of E.E.E, R.V.R \& J.C College of Engineering, India, cskoritala@ gmail.com
}

\begin{abstract}
This Paper presents the application of modern \& meticulous procedure for the measuring Partial Discharge on the GIS (Gas Insulated Switchgear). The conventional method was by the usage of analog filters and the comparison between the induced and circulating currents, here we made use of the ultra-high frequency sensors which detects the ultra-high frequency signals that were produced during the abnormal condition. The UHF sensors are placed on the Gas Insulated Switchgears at the suitable designed location. The detected signal is digitized and transmitted to the control panel via the high speed fiber optic cables. It is processed and the cause for the partial discharge is known. At site it is done along with the high voltage measurement of the GIS. The final measured value is measured in Pico coulombs.
\end{abstract}

Key words: Gas Insulated Switchgears - GIS, Partial Discharge - PD, High Voltage, Fiber Optics, SF6, UHF Ultra High Frequency Sensors

\section{INTRODUCTION}

Demand for Substations is significant due to surplus increase in the demand of energy. In order to meet this demand GIS Substations play a vital role as it reduces the space occupation in huge amount which is important criteria as the demand for land increases due to the increase in population. The transmission \& distribution losses are increasing day by day \& this can be reduced if the length of transmission is decreased. For this, substations quantity must be optimum as it strengthens the electrical grid maintaining the electrical parameters of the grid. GIS Substations are replacing the AIS substations these days because of its multiple uses. GIS substations has the switchgears which consists of SF6 gas. The ageing factor, breakdown of GIS etc., can be predetermined by the measurement of partial discharge. In simple Partial Discharge measurements can be used for

- To reduce the total number of accidental outages

- To extend the assets lifetime

- To increase energy quality
- To get most cost-effective maintenance strategies

- Inception condition faults might be detected

- To get an overall idea concerning the assets aging condition

\section{DIFFERENT PD CAUSES \& MEASUREMENT IN GIS}

The different types of PD causes can be classified as

1. Internal Discharge

2. Corona Discharge

3. Treeing

4. Cavity Discharge
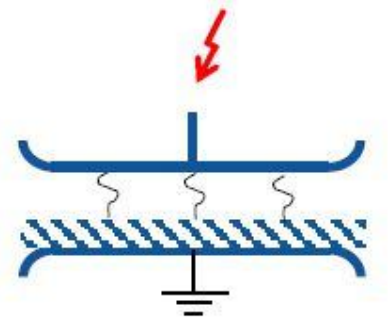

Figure 1: PD due to Internal Discharge

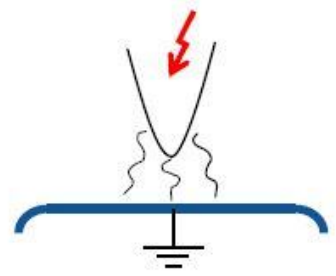

Figure 2: PD due to corona discharge

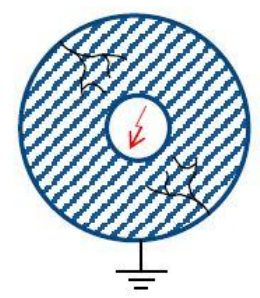

Figure 3: PD due to Treeing 


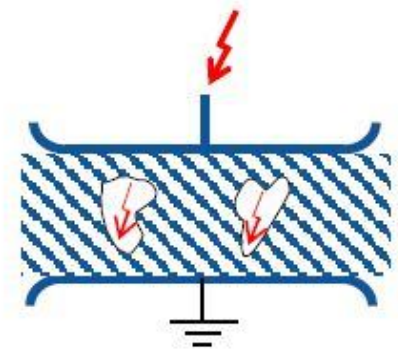

Figure 4: PD due to Cavity discharge

\section{PD MEASUREMENT IN GIS}

The different types of Partial measurements for the major equipment's like GIS, Transformers, Transmission lines that are employed usually are

- Coupling Capacitors

- High frequency Current Transformers

- Measurement on bushings

- Acoustics

- UHF Sensors

\section{UHF SENSOR MEASUREMENT IN GIS}

UHF sensor measurement replaces the traditional way of IEC measurement where the ultra-high frequency sensors are used for the measuring of partial discharge (charge) in Pico coulombs.

\section{A. UHF SENSORS:}

These UHF sensors are of type Dipole antenna \& measuring frequency band ranges from $100 \mathrm{MHz}$ to $1800 \mathrm{MHz} \&$ sensitivity of measuring the charge of Pico coulomb's less than $1 \mathrm{pC}$ for internal \& $2 \mathrm{pC}$ for external sensors.

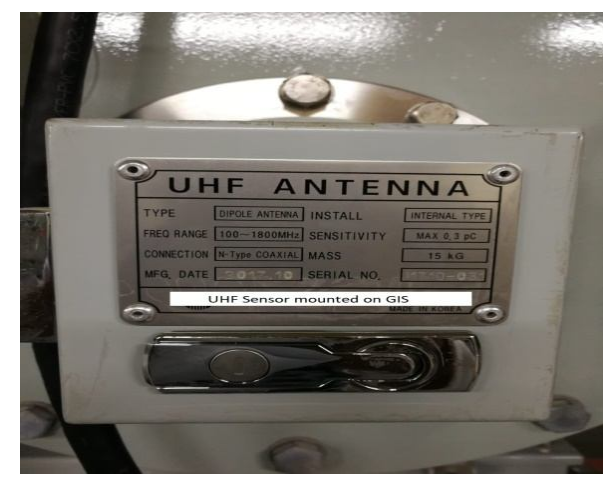

Figure 5: A typical UHF Sensor

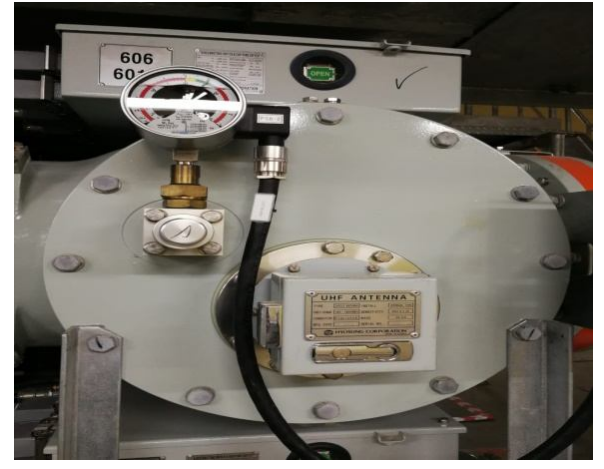

Figure 6: UHF Sensor installed on GIS

B. PD MEASUREMENT USING UHF SENSOR:

Below are the circuit representations of Conventional \& UHF types of measurements

1. Conventional Method: The PD Pulse is subjected to an attenuation phenomenon along the transmission path. Because of the attenuation, the measured value of electrical charge might be much lower than the real value involved in the PD activity.

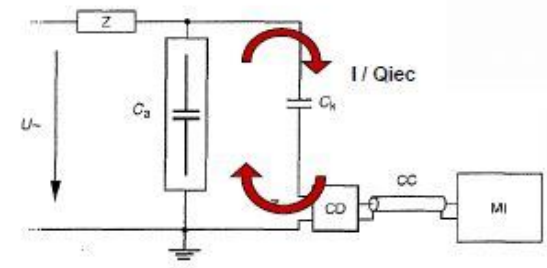

Figure 7: Circuit design of conventional method

2. UHF Sensor Method: With the usage of UHF sensor, the electromagnetic signals emitted by the PD can be detected. The strength of the signal is determined by the distance between the signal source and the location of sensor.

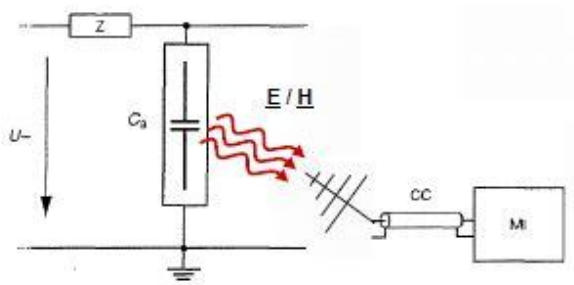

Figure 8: Circuit design of UHF sensor method

\section{PD PROPOGATION IN GIS:}

1. Conventional Method: Below is the circuit representation of PD propagation in conventional method 


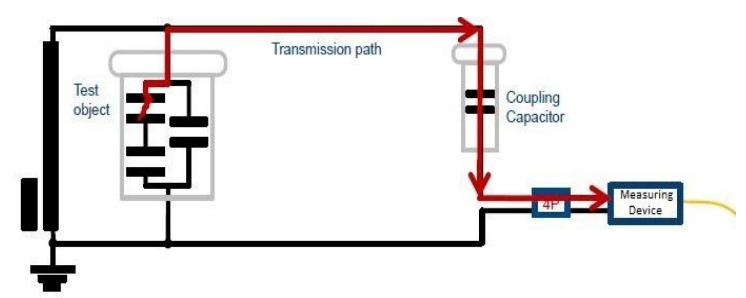

Figure 9: PD Propagation if conventional method

2. UHF Method: Below is the circuit representation of PD propagation in UHF sensor method

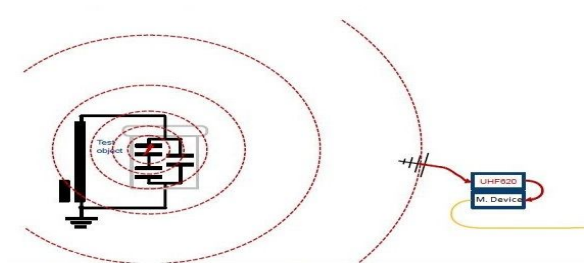

Figure 10: PD propagation in UHF sensor method.

\section{ON SITE PD MEASUREMENT}

Procedure for PD Measurement during the installation \& commissioning stage is mention below while the measurement of PD after energization was done continuously by monitoring process if any abnormalities occur, the sensors senses the abnormality and the information is passed to the PDMS panel through Fiber Optic cables, which are connected to the SAS Substation automation system (Follows the protocol of IEC 61850) by which the control center gets alerted for any abnormalities.

- Partial discharge was done to detect the possible tiny particle materials if any available \& manufacturing defects and to ensure the dielectric strength of long term of the equipment.

- It was done both phase to neutral \& phase to phase

- At the same condition as line to earth of power frequency withstand voltage measurement on the circuit, the quantity of partial discharge shall be measured according to following procedures;

- At first, the voltage was raised to the power frequency withstand voltage and maintained for 60 seconds.

- Then the voltage is decreased to Partial discharge measuring voltage without interruption.

- PD value is recorded for the respective voltage \& In general, the value is measured in Pico Coulombs $\mathrm{pC}$, which shall be less than $5 \mathrm{pC}$.

- The Partial Discharge measuring voltage is
Phase to Earth $=1.2 \mathrm{U} / \sqrt{ } 3$

Phase to Phase $=1.2 \mathrm{U}$

Phase to Earth $=110 \mathrm{kV}$ for $U=145 \mathrm{kV}, 291 \mathrm{kV}$ for $U=420 \mathrm{kV}$ Phase to Phase $=174 \mathrm{kV}$ for $145 \mathrm{kV}, 504 \mathrm{kV}$ for $\mathrm{U}=420 \mathrm{kV}$

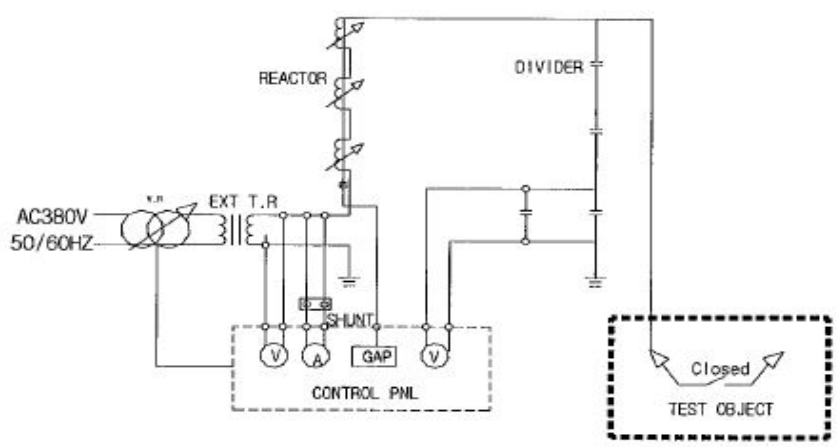

Figure 11: Control Circuit for the PD Measurement

The graphical way of representation of $145 \mathrm{kV} \& 420 \mathrm{kV}$ systems is as below:

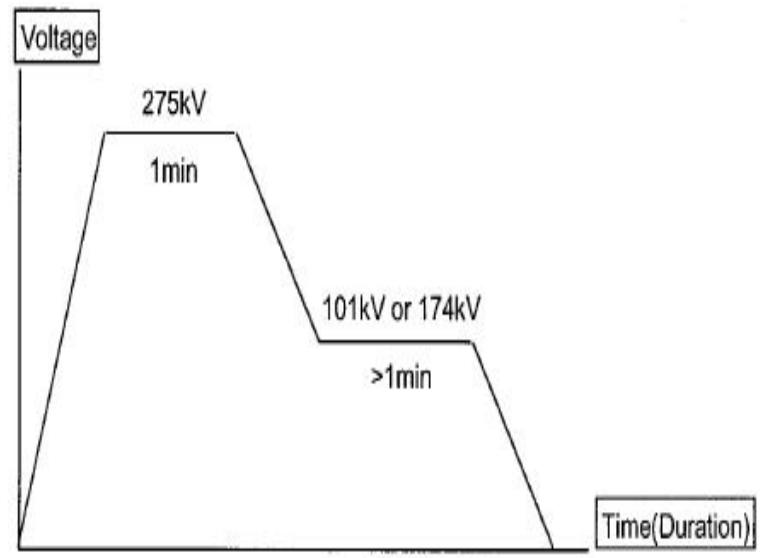

Figure 12: Voltage Vs Time graph for typical 110kV GIS

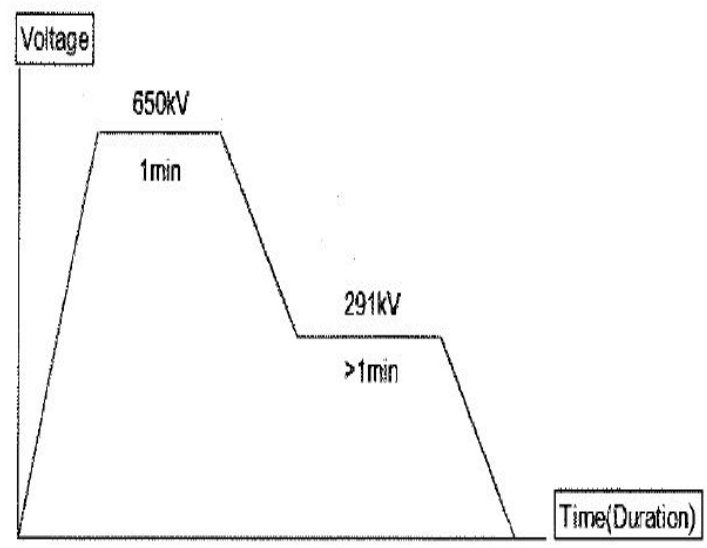

Figure 13: Voltage Vs Time graph for typical 380kV GIS 


\section{CONCLUSION}

Out of all the various PD measurement techniques, using the UHF sensors for the measurement was found to be more accurate $\&$ precise. The conventional \& old methods have the various drawbacks like time delay, less in accuracy which was overcome by using the ultra-high frequency sensors. The usage of advanced communication technology of SASSubstation Automation System made easy to communicate \& operate the commands from the far end - remote control centers. The measured PD signal value is recorded in the Pico coulomb which is checked if it is in tolerance limit. During the commissioning stage final measurement test is confirmed before the energization of GIS.

\section{ACKNOWLEDGEMENT}

This research work was done during the commissioning stage of the extra high voltage, high voltage Gas Insulated Substation projects in the Saudi Arabia which were funded by the Saudi Electricity Company.

\section{REFERENCES}

1. International Electro technical Commission: INTERNATIONAL STANDARD IEC 60270, High-voltage test techniques - Partial discharge measurement.

2. UHF Partial Discharge Monitoring for GIS", 10th International Symp. on High Voltage Engineering, Montreal, Vol. 4, p. 255-258, 1997

3. The Excitation of UHF Signals by Partial Discharges in GIS", IEEE Transactions on Dielectrics and Electrical Insulation Vol.3, No. 2, April 1996.

4. IEC 62271-203 International Standard, "Part 203- Gas insulated metal clad switchgear for rated voltages above $52 \mathrm{kV} . "$

5. Detection of Harmful Metallic particles in GIS using UHF sensors - 2008 IEEE Transactions on Dielectrics and electric insulation.

6. Lalot, J. "On-Site Acoustic Detection of Abnormalities in Metal-Clad Substations" in Gas-Insulated Substations Technology and Practice, SA. Boggs, F.Y. Chu, and N. Fujimoto, eds. Pergamon Press, 1986, p.322.

7. Pryor, B.M. "UHF Partial Discharge Detection in CIS". Working Papers of the IERE Workshop "Gas-Insulated Substations". Toronto, Canada, 30 September - 4 October 1990.

8. Leijon, MAS. and A.E. Vlastos. 'Pattern Recognition of Free Conducting Particle Motion Modes in CIS". Proceedings of the IEEE International Symposium on Electrical Insulation, 5-8 June 1988, Boston, USA.

9. Wahlstrom, B., W. Lord,K. Pettersson, R.Alvinsson, and M.A.S. Leijon. "Experiences and Considerations Regarding Erection, Testing, and Operation Availability of GIS in Sweden". CIGRE Paper 23-07,1988.
10. Konig, D. C. Neumann, H. Suiter, H. Lipken, P.Schmidhuber. "Partial Discharge Measurements of sF6 Insulated High-Voltage Metal-Enclosed Switchgear on Site. A Study Based on Fundamentals and Experiences Available Up To Now”. CIGRE Paper U-@, 1980.

11. Hadorn, P. "The Advantages of a Fully Metal-Enclosed Test Arrangement for ac Field Testing of s\&-Insulated Substations". Presented to the Spring Meeting of the Canadian Electrical Association, Toronto, March, 1981. Published in the 1981 CEA Proceedingsor available from Sprecher \& Schuh, CH-5001 Arau, Switzerland.

12. Boggs, SA., D.D. Pecena,S. Rizzetto, and G.C.Stone. "Limits to Partial Discharge Detection - Effects of Sample and Defect Geometry." in Gaseous Dielectrics V, L.G. Christophorou and D.W. Bouldin, eds. Pergamon Press, 1987. 